\title{
The Amino Acid Metabolism of Microsporum canis
}

\author{
By F. W. CHATTAWAY AND C. TOOTHILL \\ Department of Biochemistry, University of Leeds, Leeds \\ AND A. J. E. BARLOW \\ Department of Dermatology, Royal Infirmary, Huddersfield \\ SUMMARY
}

Microsporum canis utilized several single amino acids as nitrogen source during growth on a defined medium; ammonia was also used but not nitrate or methionine. Several extractants for releasing cytoplasmic contents were examined. With acetic acid (100 g./l.) as extractant the content of $\alpha$-amino nitrogen, pentose, ammonia and phosphate in the extracts was studied. A marked increase in orthophosphate with age of the mycelium was found. The free amino acid pool was examined chromatographically, qualitatively and quantitatively, during growth. Glutamic acid, glutamine, alanine and proline were the principal components of this pool at all stages of growth; proline formed $40 \%$ of this fraction at the end of the logarithmic phase of growth. Phenylalanine and tyrosine were present only in trace amounts; tryptophan was not detected in the free amino acid fraction. These three amino acids were present in mycelial protein. Glucosamine was present in increasing amounts in mycelial hydrolysates as the mould aged.

\section{INTRODUCTION}

The principal free amino acids in a number of dermatophytes have been reported (Chattaway, Toothill \& Barlow, 1961); during that work it was noted that the concentration of these amino acids varied with the time at which the mycelium was harvested from batch cultures. A quantitative study of the free amino acid pool has now been made of samples taken at intervals during growth of batch cultures of Microsporum canis with glutamic acid as nitrogen source. This was correlated with the utilization of substrates and with the amino acid composition of the mycelium. The growth characteristics of this organism were examined with defined media containing other sources of nitrogen.

\section{METHODS}

Maintenance and growth of organism. The organism, Microsporum canis strain JMcA, used in this work was obtained from Dr Jacqueline Walker (formerly of the London School of Hygiene and Tropical Medicine). The chemically defined medium used in all growth experiments was that described by Chattaway et al. (1961) with replacement as required of glutamic acid by different nitrogen sources; the total $\mathbf{N}$ content was adjusted to be the same in each medium.

The organism was maintained in stock culture on Sabouraud's broth at room temperature $\left(16^{\circ}-21^{\circ}\right)$ and was subcultured every 4-6 weeks. Inoculations for experiments were carried out by washing a culture grown on Sabouraud's broth, three times with $20-30 \mathrm{ml}$. portions of sterile water and finally homogenizing with 


\section{F. W. Chattaway, C. Toothill and A. J. E. Barlow}

$20 \mathrm{ml}$. water for 30-60 sec, by using the homogenizer of Moore \& Mason (1951); $1 \mathrm{ml}$. portions of the resulting homogenate constituted the inoculum.

Growth curves. These were constructed by inoculating eighteen $250 \mathrm{ml}$. conical flasks containing $20 \mathrm{ml}$. of appropriate medium with $1.0 \mathrm{ml}$. of homogenate. These cultures were incubated at $16^{\circ}-21^{\circ}$. At suitable intervals three flasks were removed, the mycelium harvested and its dry weight $\left(24 \mathrm{hr}\right.$. at $\left.105^{\circ}\right)$ determined. The culture filtrates from the three flasks were pooled and diluted with distilled water to the original volume of $60 \mathrm{ml}$. and subsequently examined for amino acid content, ammonia, reducing sugars and $\mathrm{pH}$ value. When nitrate was the source of nitrogen this also was estimated.

Chromatographic techniques. The solvent systems used in the two-dimensional paper chromatography and the composition of the ninhydrin spray were as used by Chattaway et al. (1961). The quantitative separation of the amino acids was carried out by ion-exchange column chromatography (Moore, Spackman \& Stein, 1958). The eluant from the column was collected with a Locarte Fraction Collector (Locarte Co., 24, Emperor's Gate, London, S.W. 7) and the fractions estimated by the method of Moore \& Stein (1954).

Preparation of mycelium. Organisms were extracted by immersion in extractant for a suitable period after harvesting mycelium on a sintered glass crucible and washing three times with water. The mycelium for hydrolysis and quantitative study of mycelial protein was obtained after extraction of cytoplasmic contents by immersion in acetic acid ( $100 \mathrm{~g}$./1.) for $4 \mathrm{hr}$; t the residue was freeze-dried. The dry material was then crushed in a mortar and extracted at room temperature (about 20 ${ }^{\circ}$ ) with chloroform + methanol ( $2+1$ by vol., Wren \& Mitchell, 1959) thus removing lipid to decrease the amount of humin formed during the subsequent hydrolysis (Block \& Weiss, 1956). The lipid-free residue was freeze-dried; this material is referred to as 'prepared mycelium'. Acid hydrolysis was effected by refluxing this prepared mycelium with a large excess of $6 \mathrm{~N}$-hydrochloric acid (Block \& Weiss, 1956), for $24 \mathrm{hr}$., excess acid being removed by distillation in vacuo. Alkaline hydrolysis of the material was effected by refluxing $150 \mathrm{mg}$. with $20 \mathrm{ml}$. barium hydroxide (140 g./1.) solution for $18 \mathrm{hr}$. Excess barium was precipitated by gaseous carbon dioxide (Block \& Weiss, 1956) and the solution taken to dryness. The residue was dissolved in aqueous iso-propanol (10 vol. + water 90 vol.).

Analytical determinations. Dry weight. The mycelium was harvested on a tared Whatman Filter paper no. 1, 3.0 cm. diam., dried for $24 \mathrm{hr}$. at $105^{\circ}$ and re-weighed. In all the growth curves shown the dry weight values are means of triplicate determinations.

Chemical estimations. Inorganic phosphorus was estimated according to Fiske \& SubbaRow (1925), pentose by the method of Mejbaum (1939), $\alpha$-amino nitrogen according to the method of Moore \& Stein (1954) with suitable correction for ammonia. Reducing sugars were estimated according to Somogyi (1952), tryptophan according to Gooder \& Happold (1954) and indole by the method of Turner (1961). Ammonia was determined by the method of Seligson \& Seligson (1951) except that a rotor was not used and diffusions were carried out overnight. Nitrate was estimated by the method of Noll (1945) as modified by Mr J. Hume (Chemistry Department, University of Leeds). For this with a sample containing up to $70 \mu \mathrm{g}$. nitrate-N/5.0 ml., $10 \cdot 0 \mathrm{ml}$. of a freshly prepared solution of brucine $(80 \mathrm{mg} . / 100 \mathrm{ml}$. 
concentrated sulphuric acid) was added; this is allowed to stand for 3-10 min., then $10.0 \mathrm{ml}$. distilled water added and the container immersed in cold water for $15 \mathrm{~min}$. The final solution was read in the Unicam Spectrophotometer SP. 600 at $410 \mathrm{~m} \mu$.

Chemicals. Unless otherwise stated all chemicals used in this work were of Analytical Reagent grade.

\section{RESULTS}

\section{Growth of the organism}

A knowledge of the growth characteristics of this strain of Microsporum canis was required in order that later results could be correlated with the 'age' of the mycelium. Therefore growth studies were carried out by using the chemically

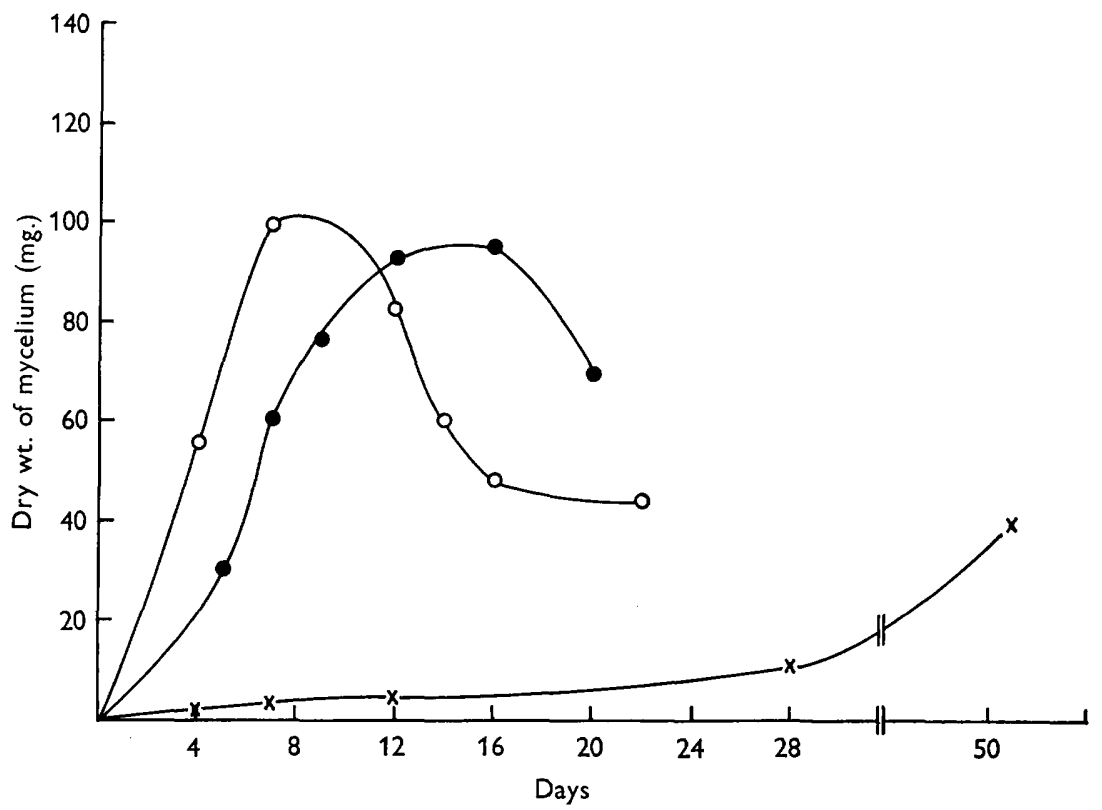

Fig. 1. Growth curves of Microsporum canis JMcA grown in a chemically defined medium containing, as nitrogen source, glutamic acid (O-O), arginine $(\mathrm{O}-\mathrm{O})$ or methionine $(x-x)$.

defined medium containing different single amino acids, as nitrogen source. The amino acids selected were: alanine, arginine, aspartic and glutamic acids and their respective amides, leucine, proline, methionine. The growth curve with glutamic acid as nitrogen source (Fig. 1) was typical of all the above amino acids with the exception of arginine and methionine; growth was more rapid with arginine, while methionine was a poor nitrogen source.

Table 1 shows the utilization of carbon and nitrogen sources, production of ammonia and $\mathrm{pH}$ changes when the above amino acids were the nitrogen sources. It can be seen that the rapid utilization of arginine, as suggested by the rapid increase in the dry weight, was confirmed and was accompanied by a rapid utilization of glucose. Of the remaining amino acids examined the rate of disappearance from the medium was similar and paralleled the rate of removal of glucose. 
724 F. W. Chattaway, C. Toothinl and A. J. E. Barlow

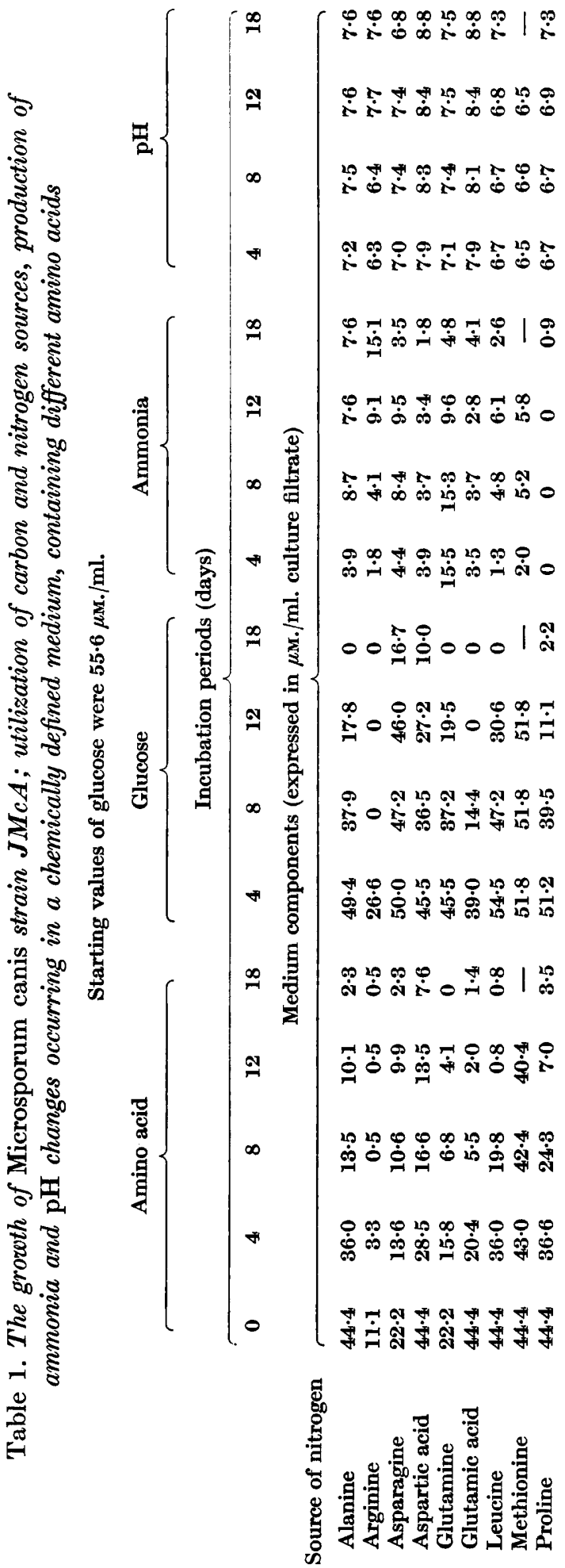


These results seem to be in agreement with those of other workers who have carried out this type of study with dermatophytes (reviewed by Stockdale, 1953) and with the genus Microsporum in particular (Johnson \& Grimm, 1951; Bereston, Robinson \& Williams, 1958), although Johnson \& Grimm did find that methionine was as good a source of nitrogen as glutamic acid.

The high ammonia concentration found during growth on arginine after the maximum dry-weight value had been achieved suggests the possible development of arginase and urease activity in the later stages of growth. Urease activity has been recorded in dermatophytes by Tate (1929) and Thompson (1955). Growth on the dicarboxylic amino acids yielded $\mathrm{pH}$ values of the medium higher than would be accounted for by ammonia production and suggests the formation of other basic substances.

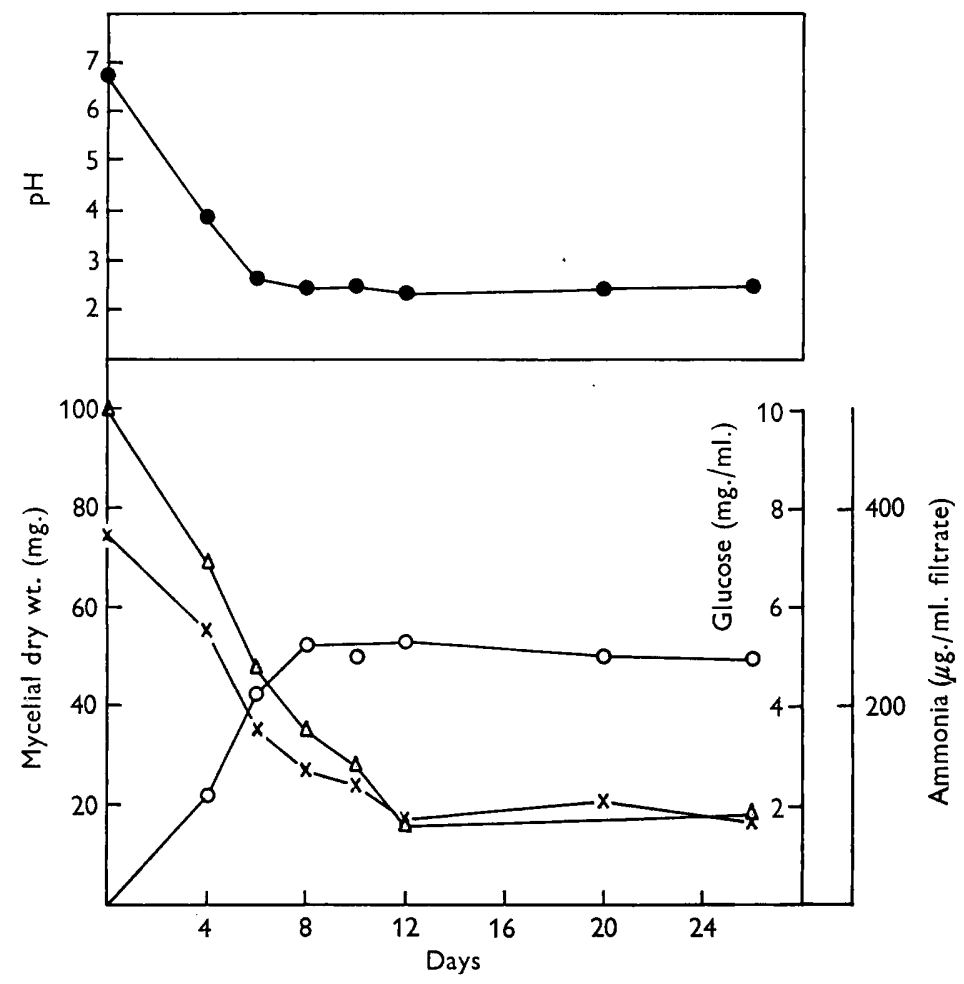

Fig. 2. Increases in dry weight $(\mathrm{O}-\mathrm{O})$, and changes in the culture medium when Microsporum canis JMcA was grown on a defined medium with ammonium nitrate as nitrogen source. Ammonia, $x-\times$; glucose, $\triangle-\triangle$; pH value

Growth of Microsporum canis JMcA with ammonium nitrate as nitrogen source showed the ability of this organism to utilize ammonia; the nitrate concentration remained constant (Fig. 2). The culture was still viable, as shown by subculture on to Sabouraud medium, after 21 days in a medium of $\mathrm{pH} 2 \cdot 5$; this $\mathrm{pH}$ decrease was due to preferential utilization of ammonia. Morton \& MacMillan (1954) found with Scopulariopsis brevicaulis that the non-utilization of nitrate in media containing ammonium nitrate was due to residual ammonia. However, attempts to grow 


\section{F. W. Chattaway, C. Toothill and A. J. E. Barlow}

$M$. canis on a medium containing nitrate as sole nitrogen source were unsuccessful, although Tate (1929) and Johnson \& Grimm (1951) reported the growth of some dermatophytes on such a medium. Two points are worth considering: (i) the finding of Fujii (1957) that nitrate utilization occurs with pleomorphic strains only, thus representing a gain in synthetic ability; (ii) the finding of Cochrane (1958) that Streptomyces spp. only metabolized nitrate when the mycelium was pre-grown with other $\mathbf{N}$ sources.

\section{Intracellular components}

Comparison of extractants. Several methods have been used to obtain cytoplasmic contents, including the use of the Mickle shaker (Gale, 1947), organic solvents (Work, 1949) and protein precipitants (Hancock, 1958). Our reasons for using acetic acid (100 g./l.) as extractant for these moulds were given by Chattaway et al. (1961). During the present work it became apparent that acetic acid was extracting cytoplasmic contents from the noulds. Thus the ultraviolet (u.v.) spectra of the extracts showed a maximum absorption at $260 \mathrm{~m} \mu$, indicative of cytoplasmic material (Salton, 1951); also similar amino acid patterns are shown by material obtained by other extraction methods (see below), several of which cause the release of intracellular amino acids from other micro-organisms. A comparison was therefore made between the efficiency of acetic acid (100 g./l. water), water alone (both at $20^{\circ}$ and at $100^{\circ}$ ), aqueous ethanol (75 vol. ethanol +25 vol. water) and by cetyltrimethylammonium bromide (CTAB; $100 \mu \mathrm{g} . / \mathrm{ml}$.). The release of inorganic phosphate, pentoses, ammonia and $\alpha$-amino nitrogen was measured. The results with aqueous acetic acid (100 g./l.) over a period of 0-20 hr. showed that the extraction period of $4 \mathrm{hr}$. originally used (Chattaway et al. 1961) was sufficient for the maximum release of all the components measured; repetition with other extractants showed a similar relationship between the rates at which other cytoplasmic components were released. The rates of release and amounts of components liberated by CTAB were different from those obtained by using other extractants, although the rate of release was slower in the early stages a greater amount was released after $7.5 \mathrm{hr}$. CTAB is known to be active in removing material attached to bacterial cell walls; for this reason it has been avoided by many workers in the preparation of cell-wall material (Professor J. Baddiley, personal communication). Therefore it was rejected as an extractant for cytoplasmic components in the present work, although extracts obtained using CTAB contained a greater number of amino acids than were seen with any other extractant. Water at about $20^{\circ}$, as one would expect, removed the smallest amount of anino acids; water at $100^{\circ}$ appears to be a rather harsh method, amides, for example, being readily hydrolysed under these conditions; the absence of glutamine was noted only when water at $100^{\circ}$ was used as extractant. Because relatively little is known about the different actions of these methods of obtaining cytoplasmic contents, or to what extent amino acids exist free within the cell, we felt justified in continuing to use acetic acid (100 g./l.) as extractant.

\section{Differences of cytoplasmic content with age of mycelium}

The release, by aqueous acetic acid (100 g./l.), of the various intracellular components was examined for mycelium harvested at different times; the results are shown in Fig. 3. It can be seen that the free $\alpha$-amino nitrogen had a maximum 
value when the dry weight of organism was maximal. The pentose concentration remained relatively constant but the inorganic phosphate and ammonia values increased steadily as the time of harvesting the crop of mycelium increased. The sharp increase in inorganic phosphate after the end of the log phase may be a manifestation of autolysis or of utilization of polyphosphate following the exhaustion of glucose in the medium. Alkaline phosphatases have been shown to be present in two dermatophytes (Microsporum canis, by Chattaway, Thompson \& Barlow, 1954; Trichophyton rubrum, Nickerson, 1951).

The clear differences in the concentration of total $\alpha$-amino nitrogen was examined. Extracts of Microsporum canis from mycelium harvested from 3 to 29 days, after suitable concentration was examined quantitatively for amounts of amino acids

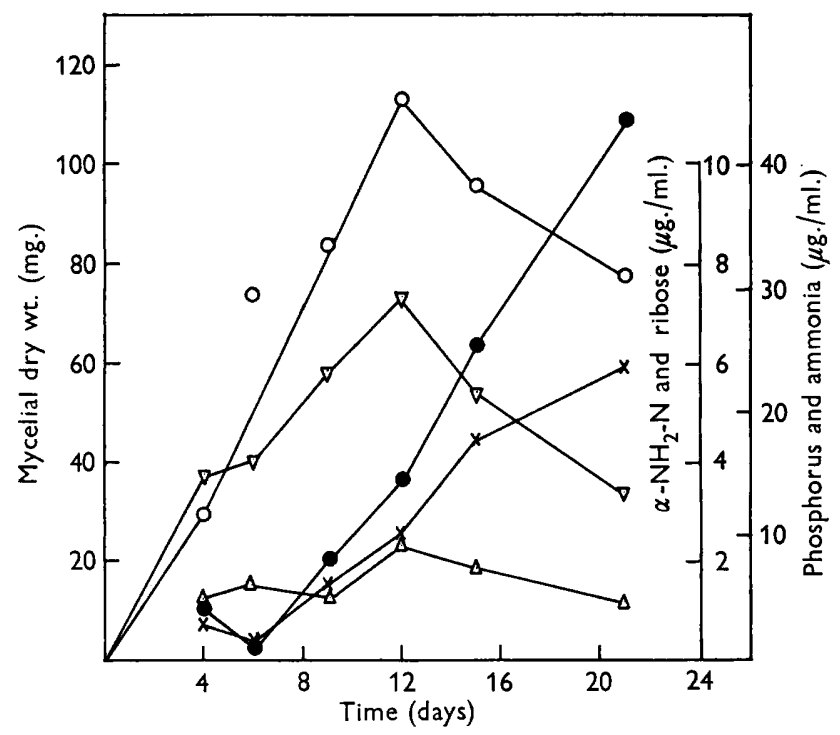

Fig. 3. The release of cytoplasmic components from Microsporum canis JMcA, harvested at different times, by acetic acid $\left(100 \mathrm{~g}\right.$. $/ 1$. water) at $20^{\circ}$ for $4 \mathrm{hr}$. The concentrations of the components are expressed as $\mu \mathrm{g} . / \mathrm{mg}$. dry weight mycelium. The growth curve $(\mathrm{O}-\mathrm{O})$ is as mg. dry-weight mycelium; phosphorus, -O; ammonia, $\times-\times$; $\alpha$ amino nitrogen, $\nabla-\nabla$; pentose, $\triangle-\triangle$.

by ion-exchange chromatography. The results of these analyses are given in Table 2. The 'glutamine' column represents glutamine + serine + threonine, because glutamine was in such high concentration that difficulty was experienced in resolving it from the two amino acids.

The results shown in Table 2 confirm those shown in Fig. 3; the maximum concentration of the pool amino acids was observed towards the end of the log phase of growth. It can be seen from these results that most of the compounds which were previously reported (Chattaway et al. 1961) were present in the highest concentrations. The relatively low concentrations of the other acids together with the rather high concentrations required to detect many of them on paper chromatograms (Block, Durrum, \& Zweig, 1958) presumably accounts for the only occasional 


\section{F. W. Chattaway, C. Toothill and A. J. E. Barlow}

detection of these amino acids as compared with the frequent occurrence of glutamine, glutamic acid and aspartic acid, proline and alanine. The high concentration of proline in the amino acid pool is striking. Only occasionally were tyrosine and phenylalanine observed in this quantitative survey; even at their highest concentrations they were present only at $0 \cdot 05-0 \cdot 20 \mu \mathrm{g}$. $/ \mathrm{mg}$. mycelium. Tryptophan was never detected.

Another feature of the results shown in Table 2 is the steadily increasing free ammonia that was extracted; a particularly sharp rise being observed after the $\log$ phase; this is in agreement with the data given in Fig. 3.

Table 2. The intracellular amino acids present in the mycelium of M. canis JMcA at various stages of growth: results expressed as $\mu$ g. amino acid/mg. dry mycelium

'Glutamine' = glutamine + serine + threonine since the high level of glutamine made separation impracticable.

\begin{tabular}{|c|c|c|c|c|c|c|c|c|c|}
\hline $\begin{array}{l}\text { Age of pad (days) } \\
\text { Dry weight (mg./pad) }\end{array}$ & $\begin{array}{l}\cdots \\
\cdots\end{array}$ & $\begin{array}{r}3 \\
10 \cdot 1\end{array}$ & $\begin{array}{r}6 \\
45 \cdot 4\end{array}$ & $\begin{array}{r}9 \\
65 \cdot 4\end{array}$ & $\begin{array}{r}11 \\
98 \cdot 5\end{array}$ & $\begin{array}{c}13 \\
108 \cdot 8\end{array}$ & $116 \cdot 0^{17}$ & 91.82 & $\begin{array}{c}28 \\
78 \cdot 0\end{array}$ \\
\hline Amino acids & & & & & & & & & \\
\hline $\begin{array}{l}\text { Aspartic acid } \\
\text { 'Glutamine' }\end{array}$ & & $\begin{array}{l}0.29 \\
-\end{array}$ & $\begin{array}{l}0.35 \\
2.06\end{array}$ & $\begin{array}{l}0 \cdot 85 \\
9 \cdot 25\end{array}$ & $\begin{array}{l}0 \cdot 41 \\
8 \cdot 70\end{array}$ & $\begin{array}{l}0 \cdot 33 \\
5 \cdot 15\end{array}$ & $\begin{array}{l}1 \cdot 11 \\
7 \cdot 15\end{array}$ & $\begin{array}{l}0 \cdot 32 \\
4 \cdot 97\end{array}$ & $\begin{array}{l}0 \cdot 14 \\
\mathrm{Nil}\end{array}$ \\
\hline Glutamic acid & & 一 & $6 \cdot 60$ & $7 \cdot 29$ & $14 \cdot 6$ & $6 \cdot 96$ & 8.55 & $1 \cdot 03$ & 0.66 \\
\hline Proline & & $8 \cdot 70$ & $1 \cdot 59$ & $2 \cdot 12$ & $\mathbf{3 \cdot 6 0}$ & $19 \cdot 40$ & $9 \cdot 95$ & $1 \cdot 44$ & $0 \cdot 68$ \\
\hline Glycine & & $0 \cdot 38$ & 0.07 & 0.74 & $0 \cdot 44$ & 0.43 & $0 \cdot 43$ & $0 \cdot 11$ & 0.05 \\
\hline Alanine & & $2 \cdot 17$ & $1 \cdot 77$ & $9 \cdot 55$ & $\mathbf{2} \cdot 80$ & $6 \cdot 88$ & $6 \cdot 76$ & $1 \cdot 22$ & 0.81 \\
\hline Cystine & & $2 \cdot 37$ & 0.35 & $7 \cdot 20$ & $0 \cdot 49$ & $3 \cdot 43$ & $1 \cdot 40$ & $0 \cdot 40$ & 0.46 \\
\hline Valine & & $0 \cdot 82$ & 0.83 & $0 \cdot 21$ & 0.71 & $1 \cdot 55$ & $0 \cdot 12$ & $0 \cdot 11$ & $0 \cdot 10$ \\
\hline Methionine & & $1 \cdot 43$ & $0 \cdot 30$ & $1 \cdot 60$ & 0.51 & $0 \cdot 60$ & $0 \cdot 60$ & $0 \cdot 08$ & $0 \cdot 14$ \\
\hline Leucine/isoleucine & & Nil & 0.21 & $2 \cdot 71$ & 0.59 & $0 \cdot 70$ & 0.73 & $0 \cdot 11$ & $0 \cdot 11$ \\
\hline Lysine & & $1 \cdot 61$ & 0.62 & $\mathbf{2 \cdot 6 0}$ & 0.77 & $1 \cdot 50$ & $1 \cdot 56$ & $0 \cdot 16$ & $0 \cdot 21$ \\
\hline Histidine & & Nil & 018 & 0.97 & $0 \cdot 29$ & 0.54 & $0 \cdot 88$ & $0 \cdot 28$ & $0 \cdot 30$ \\
\hline Ammonia & & 0.57 & 0.99 & $0 \cdot 68$ & $0 \cdot 38$ & $1 \cdot 22$ & $5 \cdot 01$ & $9 \cdot 34$ & $8 \cdot 58$ \\
\hline Arginine & & $0 \cdot 87$ & 0.30 & $2 \cdot 50$ & 0.39 & $1 \cdot 39$ & $1 \cdot 62$ & $\mathrm{Nil}$ & Nil \\
\hline
\end{tabular}

Table 3. The amino acid composition of the prepared mycelium of M. canis JMcA. Results expressed as $\mathrm{mg}$. amino acid/100 mg. prepared mycelium

$\begin{array}{lcc}\text { Amino acids } & \begin{array}{c}\text { 11-day-old } \\ \text { mycelium }\end{array} & \begin{array}{c}\text { B0-day-old } \\ \text { mycelium }\end{array} \\ \text { Alanine } & 1 \cdot 17 & 0 \cdot 15 \\ \text { Arginine } & 1 \cdot 47 & 0 \cdot 17 \\ \text { Aspartic acid } & 1 \cdot 83 & 0 \cdot 26 \\ \text { Cystine } & 2 \cdot 07 & 0 \cdot 54 \\ \text { Glucosamine } & 5 \cdot 67 & 14 \cdot 34 \\ \text { Glutamic acid } & 1 \cdot 98 & 0 \cdot 27 \\ \text { Glycine } & 1 \cdot 00 & 0 \cdot 20 \\ \text { Histidine } & 0 \cdot 67 & 0 \cdot 24 \\ \text { Leucine/isoleucine } & 1 \cdot 49 & 0 \cdot 27 \\ \text { Lysine } & 2 \cdot 60 & 0 \cdot 71 \\ \text { Methionine } & 1 \cdot 14 & 0 \cdot 25 \\ \text { Phenylalanine } & 0 \cdot 99 & 0 \cdot 11 \\ \text { Proline } & 0 \cdot 82 & 0 \cdot 32 \\ \text { Serine } & 0 \cdot 88 & 0 \cdot 31 \\ \text { Threonine } & 0 \cdot 95 & 0 \cdot 31 \\ \text { Tryptophan } & 0 \cdot 25 & 0 \cdot 05 \\ \text { Tyrosine } & 1 \cdot 56 & 0 \cdot 22 \\ \text { Valine } & 0 \cdot 26 & 0 \cdot 02\end{array}$


The amino acid composition of prepared mycelium

Samples of mycelium grown for 11 and $\mathbf{3 0}$ days on the glutamic acid medium were hydrolysed as described. The hydrolysates were analysed quantitatively for amino acids. This was done to see whether a correlation existed between the amino acid concentrations in the pool and the concentration of the corresponding amino acid in the mycelial protein. The results of these analyses are presented in Table 3.

\section{Variation of the components of the amino acid pool with the nitrogen source of the medium}

Similar patterns of amino acids were observed in extracts when single amino acids or ammonium salts served as the nitrogen source, non-detection of certain amino acids being possibly explicable by low concentrations rather than complete absence (Table 4). The most complete picture was obtained with Proteose peptone as nitrogen source in the Sabouraud medium; the occurrence of hydroxyproline

Table 4. Intracellular free amino acids present in the mycelium of M. canis $J M c A$ grown on different nitrogen sources

A record of qualitative examination of paper chromatograms of acetic acid (100 g./l.water) extracts of mycelium.

\begin{tabular}{|c|c|c|c|c|c|c|c|c|c|c|c|c|}
\hline \multirow[b]{2}{*}{$\begin{array}{c}\text { Nitrogen source in } \\
\text { the medium }\end{array}$} & \multirow[b]{2}{*}{ Glu. } & \multirow[b]{2}{*}{$\begin{array}{l}\text { Glu- } \\
\text { NH }_{2}\end{array}$} & \multirow[b]{2}{*}{ Ala. } & \multirow[b]{2}{*}{ Pro. } & \multirow[b]{2}{*}{ Leu. } & \multirow[b]{2}{*}{ Asp. } & \multirow[b]{2}{*}{$\begin{array}{l}\text { Asp- } \\
\mathrm{NH}_{2}\end{array}$} & \multirow[b]{2}{*}{ Arg. } & \multicolumn{3}{|c|}{ Ammonium } & \multirow{2}{*}{$\begin{array}{c}\text { Sabou- } \\
\text { raud } \\
\text { broth }\end{array}$} \\
\hline & & & & & & & & & $-\mathrm{SO}_{4}$ & $-\mathrm{NO}_{3}$ & $\begin{array}{l}\text { Tar- } \\
\text { trate }\end{array}$ & \\
\hline \multicolumn{13}{|l|}{ Amino acids found } \\
\hline Alanine & + & + & + & + & + & + & + & + & + & + & + & + \\
\hline Arginine & + & + & + & - & + & - & - & - & + & + & + & + \\
\hline Aspartic acid & + & + & + & + & + & + & + & + & + & + & + & + \\
\hline$\gamma$-Aminobutyric acid & - & + & - & + & - & - & - & - & + & + & + & + \\
\hline Cystine & + & + & + & + & + & + & + & - & + & + & + & + \\
\hline Glutamic acid & + & + & + & + & + & + & + & + & + & + & + & + \\
\hline Glutamine & + & + & + & + & + & + & - & - & + & + & + & + \\
\hline Glycine & + & + & - & + & + & + & + & + & + & + & + & + \\
\hline Histidine & - & + & + & + & + & + & - & - & - & - & + & + \\
\hline Hydroxyproline & - & - & - & - & - & - & - & - & - & - & - & + \\
\hline Leucine & + & + & - & - & - & - & - & + & + & + & + & - \\
\hline Lysine & + & + & + & + & + & + & + & + & - & - & + & + \\
\hline Methionine/valine & + & + & - & + & + & + & + & + & + & + & + & + \\
\hline Ornithine & - & - & - & - & - & - & - & + & - & - & - & - \\
\hline Proline & + & + & + & + & + & + & + & + & + & + & + & + \\
\hline Serine & + & + & - & + & + & + & + & + & + & + & + & + \\
\hline Threonine & + & + & + & - & - & + & + & + & + & + & + & + \\
\hline Tyrosine & + & + & - & - & - & - & - & - & - & - & - & - \\
\hline
\end{tabular}

in these extracts is notable. This seems to be the first report of the presence of this compound in extracts of dermatophytes, although Hoare (1955) has detected it in aqueous ethanol extracts of Sarcina lutea.

The occurrence of ornithine in the extract from mycelium grown on arginine is not surprising because of the importance of this amino acid in the urea cycle, the operation of which is suggested by the high concentrations of ammonia found in these cultures (Table 1 ). The almost complete absence from the chromatograms of tyrosine and the absence of phenylalanine and tryptophan was noticeable. 


\section{DISCUSSION}

The qualitative differences in the free amino acid pool with changes in nitrogen source in Microsporum canis (Table 4) were in keeping with the results of Simonart \& Chow (1953) with Aspergillus oryzae. They found that glutamic acid, alanine, aspartic acid, glutamine and glycine were present in organisms grown on all nitrogen sources, that growth on arginine gave ornithine in the pool and that a complex nitrogen source yielded a more comprehensive collection of amino acids in the pool. That this last finding is not always the case was shown by Fujii \& Yoshimura (1957) who found more amino acids in extracts of Trichophyton mentagrophytes when this organism was grown on a defined medium containing glutamic acid than when it was grown in Sabouraud medium; Okazaki \& Tamemasa (1953) only detected six amino acids during the growth of $T$. asteroides on the latter medium. $\gamma$-Amino butyric acid was found in all extracts from growth on ammonium salts where the $\mathrm{pH}$ value of the medium decreased to small values during growth, but only rarely from growth on amino acids. Simonart \& Chow (1954) found that $A$. oryzae only formed $\gamma$-amino butyric acid when the medium was below $\mathrm{pH} 4$. However, growth of Microsporum canis on Sabouraud medium became alkaline, but $\gamma$-aminobutyric acid was readily detected in the amino acid pool.

The quantitative study of the free amino acids during the growth of Microsporum canis with glutamic acid (Table 2) confirms the qualitative studies in that proline, alanine, glutamic acid and glutsmine were found to be the most abundant components; the general picture was of increasing concentrations of free amino acids during the logarithmic phase of growth and a rapid decrease thereafter. This pattern is like that recorded by Pillai \& Srinivasan (1956) for Aspergillus flavus. Proline, alanine and glutamine are all closely related metabolically to glutamic acid; this may explain the high concentration observed. These four amino acids comprised $80-90 \%$ of the free amino acids, except that after 6 and 28 days growth the value was $60 \%$. After 13 days of growth proline alone comprised $40 \%$ of the free a mino acid fraction; this may indicate some particular function for this amino acid. The yellow pigment characteristic of rnany strains of Microsporum canis was present in much greater amounts in $M$. canis strain JMcA when this was grown with proline as sole nitrogen source than when it was grown on any other single amino acid. The high concentration of glutamine may reflect its utilization as a source of glucosamine6-phosphate (Leloir \& Cardini, 1953), a precursor of chitin. Chitin is a major component of the mycelial cell wall of dermatophytes (Blank, 1953); its increased concentration in ageing mycelium is reflected in the three-fold increase in glucosamine seen in the hydrolysate of 30-day mycelium as compared with that of 11-day mycelium (Table 3).

The amino acids found in hydrolysed mycelium of Microsporum canis are similar to those found for numerous other micro-organisms and resemble those found by Hare (1953) in 8 dermatophytes, except that Hare did not detect tryptophan. This was present (Table 3 ) in low concentration in $M$. canis stain JMcA. Neither tryptophan, tyrosine or phenylalanine were found in the free amino acid fractions although all three were present in the mycelial protein; these amino acids must be utilized rapidly by $\boldsymbol{M}$. canis following synthesis and thus were not present in detectable concentrations in the free state. 


\section{REFERENCES}

Bereston, E. S., Robinson, H. \& Williams, S. A. (1958). The quantitative nutritional requirements of the genus Microsporum. J. invest. Derm. 30, 63.

BLANK, F. (1953). The chemical composition of the cell walls of Dermatophytes. Biochim. biophys. Acta, 10, 110.

Block, R. J., Durrum, E. L. \& Zweig, G. (1958). A Manual of Paper Chromatography and Paper Electrophoresis. 2nd ed. New York: Academic Press Inc.

Block, R. J. \& WeIss, K. (1956). Amino Acid Handbook, 1st ed. Springfield, Ill., U.S.A.: C. C. Thomas.

Chattaway, F. W., Thompson, C. C. \& Barlow, A. J. E. (1954). Enzymes of Microsporon canis. Biochim. biophys. Acta, 14, 583.

Chattaway, F. W., Toothill, C. \& Barlow, A. J. E. (1961). Intracellular free amino acids of certain dermatophytes. Nature, Lond. 190, 1731.

Cochrane, V. W. (1958). Physiology of Fungi, 1st ed. New York: John Wiley and Sons Inc.

Fiske, G. H. \& SubbaRow, Y. (1925). The colorimetric determination of phosphorus. J. biol. Chem. 66, 375.

FuJIr, T. (1957). Biochemical studies on pathogenic fungi: nutritional studies with special reference to its pleomorphism. Pharm. Bull. (Tokyo), 5, 503.

Fusir, T. \& Yoshimura, T. (1957). Biochemical studies on pathogenic fungi. IX. Free amino acids of Trichophyton gypseum. Acta Sch. Med. Univ. Gifu, 5, 489.

GaLe, E. F. (1947). The assimilation of amino acids by bacteria. 1. The passage of certain amino acids across the cell wall and their concentration in the internal environment of Streptococcus faecalis. J. gen. Microbiol. 1, 53.

Gooder, H. \& Happold, F. C. (1954). The tryptophanase-tryptophan reaction. The nature of the enzyme-coenzyme-substrate complex. Biochem. J, 57, 369.

HANCOCK, R. (1958). The intracellular amino acids of Staphylococcus aureus: release and analysis. Biochim. biophys. Acta, 28, 402.

HARE, P. J. (1953). The amino acid composition of eight dermatophyte fungi. Lancet, ii, 1238.

Hoare, D. S. (1955). The amino acid composition of Sarcina lutea grown on different media. J. gen. Microbiol. 12, 534.

Johnson, S. A. M. \& Grimm, N. Y. (1951). The amino acid requirements of Microsporum fulvum. J. invest. Derm. 17, 305.

Leloir, L. F. \& Cardini, C. E. (1953). The biosynthesis of glucosamine. Biochim. biophys. Acta, 12, 15.

Mejbaum, W. (1939). Über die Bestimmung kleiner Pentosemengen insbesondere in Derivaten der Adenylsäure. Hoppe-Seyl. Z. 258, 117.

Moone, W. T. \& MAson, B. (1951). Blender for the preparation of mycelial inocula. J. gen. Microbiol. 5, 516.

Moore, S., Spackman, D. H. \& Stein, W. H. (1958). Chromatography of amino acids on sulphonated polystyrene resins. An improved system. Anal. chem. 30, 1185.

Moore, S. \& Stein, W. H. (1954). A modified ninhydrin reagent for the determination of amino acids and related compounds. J. biol. Chem. 211, 907.

Morton, A. G. \& MacMillan, A. (1954). The assimilation of nitrogen from ammonium salts and nitrate by fungi. J. exp. Bot. 5, 232.

Nickerson, W. J. (1951). Physiological bases of morphogenesis of animal disease fungi. Trans. N.Y. Acad. Sci. 13, 140.

NoLl, C. A. (1945). Determination of nitrate in boiler water by brucine reagent. Industr. Engng Chem. (Anal.), 17, 426.

Okazaki, K. \& Tamemasa, O. (1953). Free amino acids in the dermatophytes. Pharm. Bull. (Tokyo), 1, 405.

Pillai, N. C. \& Srinivasan, K. S. (1956). The amino acid metabolism of Aspergillus flavus. J. gen. Microbiol. 14, 248.

Salton, M. R. J. (1951). The adsorption of cetyltrimethylammonium bromide by bacteria, its action in releasing cellular constituents and its bactericidal effects. J. gen. Microbiol. 5, 391. 


\section{F. W. Chattaway, C. Toothill and A. J. E. Barlow}

Seligson, D. \& Seligson, H. (1951). A microdiffusion method for the determination of nitrogen liberated as ammonia. J. Lab. clin. Med. 38, 324.

Simonart, P. \& Chow, K. Y. (1953). Étude du metabolism d'acides aminés chez Aspergillus oryzae. II. Acides aminés libres du mycélium cultivé sur divers acides aminés. Antonie van Leeuwenhoek J. Microbiol. Serol. 19, 245.

Simonart, P. \& Chow, K. Y. (1954). Étude du metabolism d'acides aminés chez Aspergillus oryzae. III. Acides aminés libres dans le mycélium cultivé sur diverse sources de carbone en presénce d'ammonique. Antonie van Leeuwenhoek J. Microbiol. Serol. 20, 174.

SoмоGyі, M. (1952). Notes on sugar determination. J. biol. Chem. 195, 19.

Stockdale, P. M. (1953). Nutritional requirements of the dermatophytes. Biol. Rev. 28, 84.

Tate, P. (1929). On the enzymes of certain dermatophytes or ringworm fungi. Parasitology, 21, 31.

Thompson, C. C. (1955). Studies in the metabolism of pathogenic fungi. Ph.D. Thesis, University of Leeds.

Turner, J. M. (1961). A new reagent for the assay of indole in the tryptophanase reaction. Biochem. J. 78, 790.

Work, E. (1949). Chromatographic investigation of amino acids from micro-organisms. Biochim. biophys. Acta, 3, 400.

Wren, J. J. \& Mitchell, H. K. (1959). Extraction methods and an investigation of Drosophila lipids. J. biol. Chem. 234, 2823. 